\title{
Soil Water Balance Model CRITERIA-1D in SWAMP Project: Proof of Concept
}

\author{
Giulia Villani, Paolo Castaldi, Attilio Toscano, \\ Camilla Stanghellini, Tullio Salmon Cinotti \\ University of Bologna \\ Bologna, Italy \\ \{giulia.villani3, paolo.castaldi, attilio.toscano, \\ tullio.salmoncinotti, camilla.stanghellini\}@unibo.it
}

\author{
Fausto Tomei \\ Arpae-SIMC \\ Bologna, Italy \\ ftomei@arpae.it
}

\author{
Rodrigo Filev Maia \\ Centro Universitário da FEI \\ São Bernardo do Campo (SP), Brazil \\ rfilev@fei.edu.br
}

\author{
Markus Taumberger \\ VTT Technical Research Centre of Finland Ltd \\ Oulu, Finland \\ markus.taumberger@vtt.fi
}

\author{
Paola Zanetti, Stefano Panizzi \\ Consorzio di Bonifica dell'Emilia Centrale \\ Reggio Emilia, Italy \\ \{pzanetti, spanizzi\}@emiliacentrale.it
}

\begin{abstract}
The aim of this work is to present the first results obtained by means of the new validation of the water balance and crop development model CRITERIA-1D, specifically set up for the SWAMP (Smart Water Management Platform) platform on one of the pilots, in the framework of the SWAMP project, aimed at providing support for precision irrigation in agriculture. The platform consists of an IoT solution for monitoring the farming and irrigation systems combined with data analytic solution to assess the irrigation need of plants, and support for irrigation planning and water distribution both at farm and district level. CRITERIA-1D has been tested on two test cases for the Italian pilot, located in the land reclamation and irrigation consortium of Emilia Centrale (North Italy). The comparison of crop irrigation water needs computed by CRITERIA-1D with actual irrigation performed by farmers has been carried out, together with a comparison of crop water stress. The analysis has shown that for both the test cases the two data series are comparable, but some differences have been highlighted: in some cases the farmer irrigation is not decided on the basis of the actual water needs of the crops but on farm management decisions. In addition, if the total annual volumes of irrigation of the two series are comparable, the scheduling is different, where the observed irrigation data bring the crop to too high (or too low) level of water stress. Thus, the present work has shown that the application of CRITERIA-1D simulation model is a valid tool to support irrigation management because it allows an optimal use of the resource avoiding crop yield losses with a rational irrigation scheduling.The reliability of these outcomes sets the conditions for further exploitation of the model in the future, firstly for its integration into the SWAMP platform.
\end{abstract}

\section{INTRODUCTION}

Nowadays agricultural sector is the most water demanding economic sector, therefore a rational management of water is needed. For the European region, in particular for Mediterranean areas, the climate change has a deep impact on water resources; this makes mandatory the application of tools for a better management of water. In fact, one of the consequences of climate change is the alteration of rainfall trends in terms of timing and quantity [1]. Such alterations make the irrigation management particularly difficult, so that a constant monitoring and adaptation is needed, in order to support traditional agricultural practices.

Furthermore, irrigation and crop yieldin terms of quantity and quality are closely related [2], so that water management is both the adaptation tool to tackle effects of climate change and the factor that ensures food production.

For these reasons, a branch of smart agriculture is devoted to the rational management of irrigation. Tools like DSS (Decision Support System), environmental sensors to measure soil moisture and other properties have been developed for this aim.

In this context, the SWAMP (Smart Water Management Platform) project (H2020 - EU.2.1.1.-INDUSTRIAL LEADERSHIP - Leadership in enabling and industrial technologies - Information and Communication Technologies (ICT) - GA: 777112) is aiming at developing IoT based methods and approaches for smart water management in the precision irrigation domain. SWAMP is an Europe-Brazil cooperation project and it aims at testing the IoT methodologies into four pilot areas that are characterized by different peculiarities and are representative of different waterrelated challenges for agriculture optimization. The pilots are two in Europe (Italy and Spain) and two in Brazil. SWAMP aims at improving precision irrigation techniques and water management by increasing the knowledge and monitoring of crop condition, adjusting the irrigation and water distribution practices according to soil and weather conditions as well as in relation to water availability. The partnership's work aims at guaranteeing that SWAMP solutions are flexible enough to adapt to different contexts and to be replicable in different 
locations and settings; thus, the project brings together a series of challenges inherent to both IoT and agriculture communities.

The SWAMP project develops a platform for precision irrigation that consist of an IoT solution for monitoringthe farming and irrigation systems. The platform includes a drone supported data collection from fields, a cloud-based datacollection tool, a data analytic solution for analysing the water need of plants and irrigation needs. This toolbox is aimed at supporting irrigation planning and water distribution both at farm and district level. The platform will beadapted for pilot sites and the project will develop mobile applications for both farmers and irrigation water procurement and allocation agencies.

With this in mind, one of the cores of the project is the integration in the SWAMP platform of a simulation model to assess and forecast the crop irrigation need, in order to have an assessment from the field of the required water. This information will be combined with the hydraulic network modelingin order to plan a scheduling optimizing water distribution. This kind of tool has to be conceived within SWAMP as a virtual digital twin.

In general terms, a digital twin is a digital representation of a physical system that allows real-time interaction (monitoring and control) with it, through a virtual entity. The digital information of this virtual entity is a "twin" of the information that is embedded within the physical system itself [3].

For the application of the SWAMP project, the digital twin concept is utilized because, in a complex environment like the agricultural field, it is difficult and expensive to monitor all the variables that influence the irrigation management.

The SWAMP digital twin is built hierarchically from Soil and Crop Agents that feed information into a Field Avatar which is the high-level digital representation of an agricultural field (see Fig. 1). Sensors that collect real-world data and models that simulate / predict the behavior of the soil and crops provide the input data for the different components. The water need estimation model is a key component that helps computing the irrigation needs of crops based on soil water balance and crop developmentmodels.

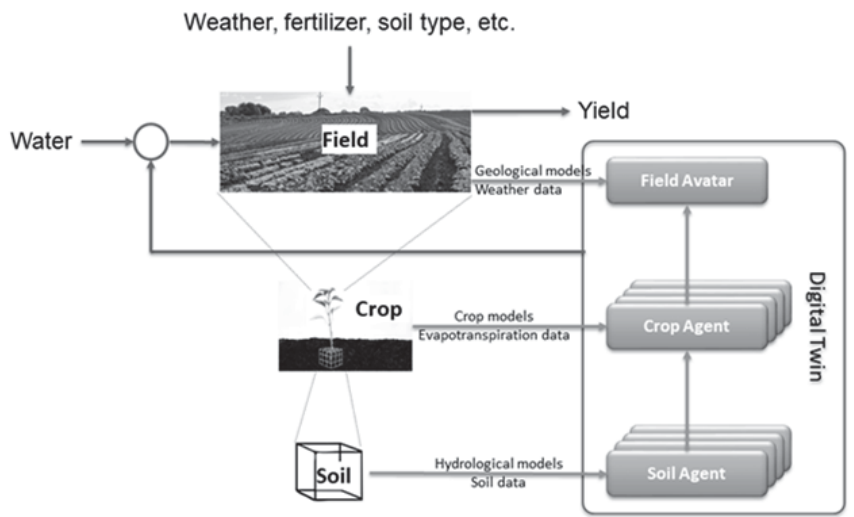

Fig. 1. Digital twin concept in SWAMP

The aim of this work is to carry out a new validation of the water balance and crop development model CRITERIA-1D, specifically set up for the SWAMP platform on the Italian pilot of the project.

In more details, the comparison of crop irrigation water needs computed by CRITERIA-1D (referred to hereinafter as SWB simulation - Soil Water Balance simulation) with actual irrigation (referred to hereinafter as observed irrigation) for two case studies is performed; moreover, an analysis on the crop status according to the different irrigation regimes (simulated by the model and carried out by the farmer) in terms of water stress is shown.

The paper is organized as follow: the section II addresses in general terms the different soil water balance approaches, focusing on the empirical approach and describing in more details CRITERIA-1D. Within section III, part A describes the main features of the SWAMP pilot area on which the model has been tested, with a highlight on the two case studies.Then, part B presents an insight of the input data used to set up the simulations of the model and to carry out the analysis is provided. Section $C$ is devoted to the description of the assessment methodology used to evaluate the results, that are described by means of plots in the following section, whereas section D the discussion of results is provided. Finally, final remarks and future developments are reported in the section IV.

\section{SOIL WATER BALANCE MODEL AND SIMULATION}

In general terms, the factors that determine a soil water balance in an agricultural field are physical and ecophysiological processes such as infiltration, redistribution, evaporation and transpiration that occur simultaneously [4] and interacting one with another in the soil crop and atmosphere. This is described in Fig. 2.

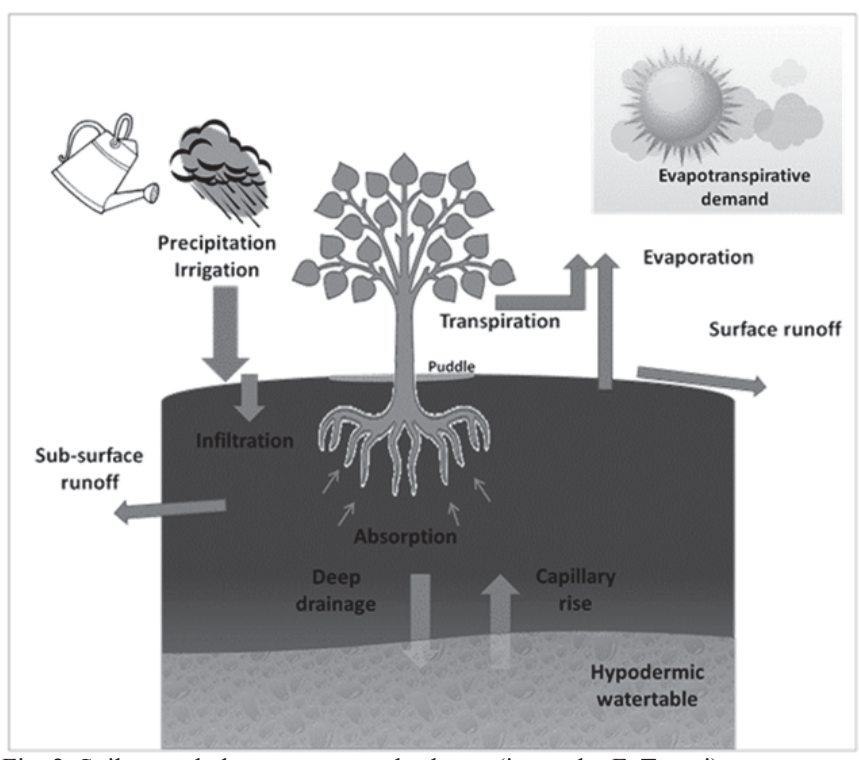

Fig. 2. Soil water balance conceptual scheme (image by F. Tomei)

The aim of a soil water balance is to know at any time the amount of water in soil available to the crop [5]. Most of the water that is absorbed by plants is lost in atmosphere for the effect of transpiration that occur in stomatal openings of crop leaves. The rate of the daily turnover of water is considerable so that, if soil moisture taken up by roots is not replenished, the 
soil will dry and the plant will wilt, with a drastic drop of dry matter production [6].

There are several approaches that can be adopted in order to assess a soil water balance, for instance empirical approaches or other techniques based on model driven methods such as proposed in FAO (FAO, paper 56), or even data driven models based on machine learning and automation and control techniques, such as genetic algorithms [7] and control loop techniques. Both modelling strategies may take advantages from soil and weather monitoring.

Data driven models are built based on parameters relevant to the observed phenomenon (such as soil properties and weather for irrigation), and such models could be organized in order to keep relationships between the variables of the model and the physical phenomenon, or vice versa without taking into account such relationship. For SWAMP project perspective it is relevant to use the first type of data driven model, since it is important to understand how each parameter affects the algorithm results. Control loop techniques approach may use the classical PID algorithm [8] to keep the soil water balance in the appropriate levels, or even use genetic algorithms, fuzzy logic and other techniques to optimize the use of resources [9, 10]. An example of application of such methodology has been tested in 2017 by Molina et al. [17]. In their work, the authorsshowed how the sliding mode control can be employed for an irrigation problem where the control objective is to regulate the water content in the soil.The application of data driven models to SWAMP case study goes beyond the scope of this paper. However, the present analysis of "SWAMP digital twin of the field" behavior, in terms of water need and water stress, might be the basis for the future development of an automatically controlled management strategy.

On the other hand, the empirical approach consists, in simple terms, in the calculations by means of empirical equations ofthe amount of water from rain or irrigation that infiltrates into the ground. The infiltration process depends on surface conditions, on the hydrological characteristics of the first layers of soil and its water content. The water that cannot be absorbed from the soil is collected in puddles formed by surface roughness. Once puddles are filled, surface runoff occurs.

The processes of storage and infiltration are driven by soil water potential differences. Each soil horizon is characterized by its water retention curve. According on the water content, one layer can retain water or transfer it to the layer below. If shallow water table is present, there may also be a supply of water to deeper layers due to capillary rise.

The presence of a crop produces water loss in the root zone through transpiration, and simultaneously reduces evaporation loss in the surface layers of soil. Depending on the type of soil, its water content and the phenological stage of the crop, the water in the soil is more or less available to plants, thus affecting its transpiration rate.So that, once the crop parameters are properly set, it is possible by means of the soil water balance to forecast the crop water needs not fulfilled by the soil water content, that have to be provided by irrigations.

For this proof of concept within theSWAMP project, we have used the CRITERIA-1D model developed by ArpaeSIMC [11]. The software follows the approach of Driessen [12] and Driessen and Konijn [13] but it assumes a multilayered soil and explicitly computes approximate values of daily actual evaporation and transpiration, water flows between layers, deep drainage, surface and subsurface runoff and capillary rise.

CRITERIA-1D is a code written in C++ language with QT libraries, thus it can be compiled on several platforms. It has a LGPL license so that it is opensource and it is available within the CRITERIA-3D distribution on Github. As input it requires soil and crop parameters and daily meteorological data, namely minimum and maximum temperatures, total precipitation and, if available, estimated potential evapotranspiration and hypodermic water table depth, as will be described in the follow.

The model has been used in several past works, calibrated and validated on test cases [14].

\section{TEST CASE IMPLEMENTATION}

\section{A. Test area features}

1)Overview: The study area selected for the SWAMP project and for which the simulations have beencarried out is the San Michele-Fosdondo irrigation district managed by the Consorzio di Bonifica dell'Emilia Centrale (CBEC), one of the eight reclamation consortia of the Emilia-Romagna Region, Northern Italy.The pilot district covers an area of about 892 ha (320 ha of irrigated area) and is locatedbetween the municipalities of Bagnolo and Correggio, near the city of Reggio Emilia.

The district is named after the two main canals that pass through it: San Michele Canal and Fosdondo Canal (Fig.3). The water supply during theirrigation season is ensured by means of those two canals and a dense network ofminor streams.

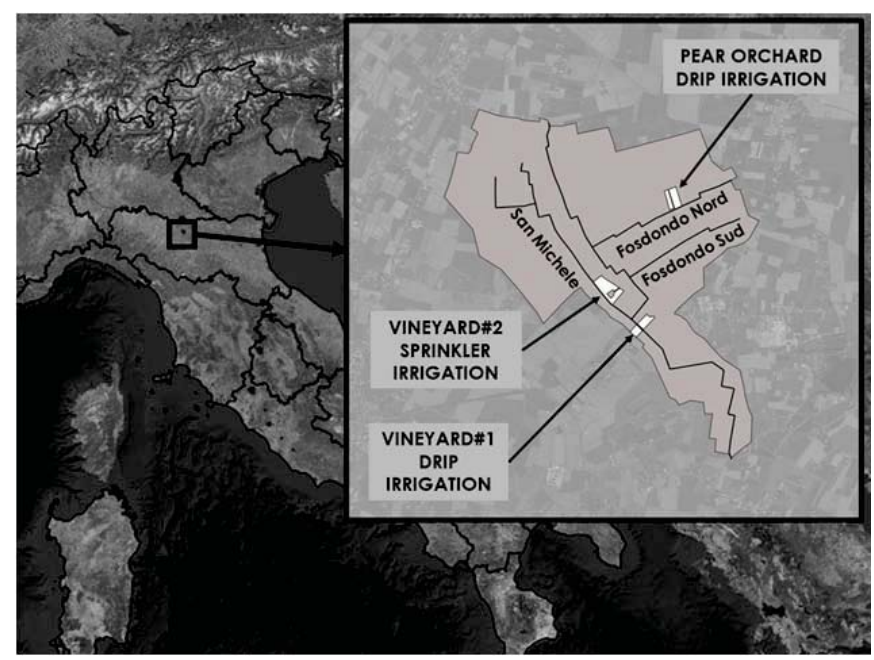

Fig. 3. Location map of the study area

The region is located in the Po plain and characterized by a temperate continentalclimate, it is mainly devoted to agriculture, with a widespread presence of smalland medium-sized farms.In general terms, the soil in the area is characterized byalluvial carbonate sediments, the clay-loamy soil texture is the most common.

2) Crops: The area is specialized in high value agri-food products such as Parmigiano Reggiano, Lambrusco and fruit. 
Thus, among the 63 farms of the district, 2 vineyards and 1 pear orchard wereselected as SWAMP test areas. The reasonof this choice is due to the importance of thecrops in the area and because different irrigation methods are applied (i.e. sprinkler andmicro-irrigation systems).

3) Irrigation methods:Each test areais characterized by a different irrigation system in order to test the SWAMP platform in different conditions: the pear orchard is equipped with a drip irrigation system, as well as vineyard \#1, while vineyard \#2 is irrigated with an above-canopy sprinkler system.

4) Selected test cases:As proof of concept, the analysis is carried out on two test cases in the CBEC Italian pilot: the pear orchard test (Pyrus communis L.) cv. Abate and the vineyard\#2test (Vitis vinifera L.) cv. Lambrusco Salamino, irrigated respectively by drip irrigation and sprinkler irrigation.

The pear orchard location is $44.791091,10.736216$, whereas the vineyard location is44.778366 10.721599 (see Fig. 3).

5) Observed irrigation data: CBEC database reports, for each fields, technical features of the irrigation plants (water flow rate and the duration of irrigation in hours) and the size of the fields. For the pear orchard we have derived the water flow rate of the irrigation plant from the more precise data referring to 2018. The CBEC database collects data from 2013 but for some fields data collected during the first years are not reliable, as in the test case of vineyard\#2. These data have been used as comparison with the model simulation.

\section{B. Input data for soil water balance model}

1) Weather data:Daily weather data of air temperature (minimum and maximum) and precipitation come fromthe meteorological analysis ERG5 grid of Emilia-Romagna, developed by Arpae-SIMC. The analysis grid has a resolution of $5 \mathrm{~km}$ and for the SWAMP analysis the cell 01015 S.Michele (coordinates: 44.7675, 10.7097775) has been selected.

2) Watertable data:The pear orchard is located in an area influenced by the shallow watertable, whereas the vineyard is located in a higher part where watertable has no effect.Sincewatertable has to be taken into account in order to compute a reliable water balance,data from the monitoring network of the shallow watertable of Emilia-Romagna has been used. For the test case on pear orchard, the measuring point is 06RE. Measured data are then elaborated by means of an empirical algorithm [16]in order to obtain a continuous daily series.

3) Crop parameters:Default parameters for pear orchard and vineyard in CRITERIA-1D model (database: modelparameters.db) have been used.

4) Soil data: Soil data are provided by the Geological, seismic and soil survey of Emilia-Romagna regional database. The soil that characterize the area is SMB1 (Sant'Omobono1), a typical silty loam soil of Emilia-Romagna plain area(database: soil_ER.db).

\section{Assessment methodology}

Water stress coefficient, Ks [15], adapted for the present analysis, has been selected as assessment indicator to perform the comparison between SWB simulation and observed irrigation for the two test cases (pear orchard and vineyard) above described.

The water stress coefficient by FAO is expressed as:

$$
K_{S F A O}=\frac{E T_{\text {actual }}}{E T_{\max }}
$$

Where $E T_{\text {actual }}(\mathrm{mm})$ is the actual evapotranspiration and $E T_{\max }$ $(\mathrm{mm})$ is the maximum evapotranspiration.Because of the subdivision of evapotranspiration in the components (transpiration and evaporation) in CRITERIA-1D, here we express Ks (-) as limited to the transpiration of the crop and we define it as the complementary of $\mathrm{Ks}_{\mathrm{FAO}}$. Therefore $\mathrm{Ks}$ is defined as:

$$
K_{s}=1-\frac{T_{\text {actual }}}{T_{\max }}
$$

so that if there is no water stress, $\mathrm{Ks}=0$.

\section{Results}

1) Pear test case: Fig. 4 shows the temporal plot (from 2013 to 2017) of the total irrigation sum per year for the pear orchard test case simulated by the SWB in gray and distributed by the farmer in black. From 2013 to 2016 the observed data reach constant values, with the exception of 2017. The typical volume that farmer is used to distribute (about $200 \mathrm{~mm}$ ) is confirmed by the model simulation in years with 'normal' irrigation water need $(2013,2015,2016)$. During the wet summer of 2014, the observed irrigation has been higher than the necessary (of about $100 \mathrm{~mm}$ ). The model confirms also the decision of the farmer to irrigate twice than the mean value in 2017, a very dry year, where simulated data show a remarkable increase in the trend of observed data.

It is worthy to mention that the behavior of the farmer shows a constant trend, that means a conservative approach for the irrigation distribution; the difference in terms of volumes for 2017 is due to the severe drought that affected the area since the start of the spring (i.e.: March 2017).

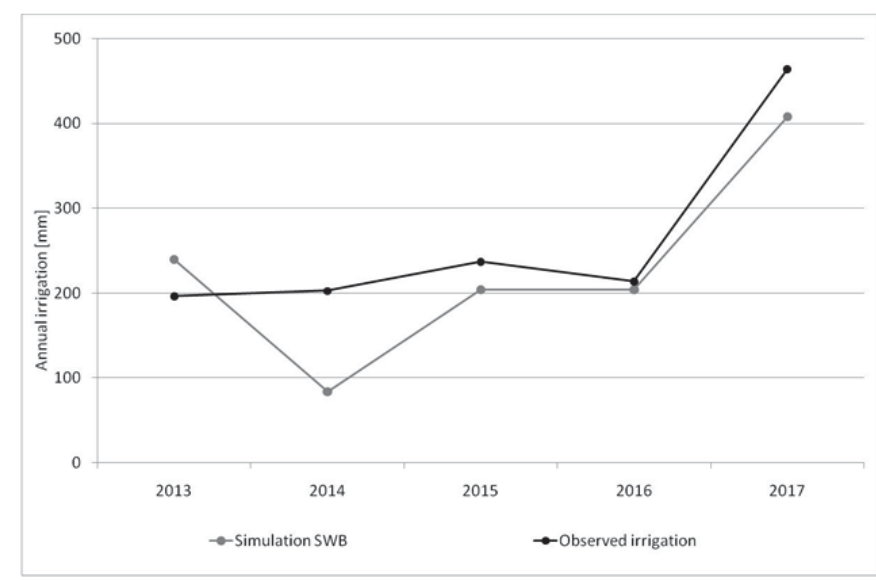

Fig. 4. Irrigation annual sum (mm) for pear orchard (cv. Abate) from2013 to 2017. Comparison between simulation of SWB model and observed irrigation; the SWB model results are plotted in gray, whereas the observed data are in black 
The plot in Fig. 5 represents the irrigation scheduling (cumulated in $\mathrm{mm}$ ) focused on the irrigation season 2016 (from June to November) for the pear test case. In this case study the analysis is focused on 2016, an average in terms of irrigation water needs. The gray line refers to simulated data whereas the black line refers to observed irrigation. The total amount of irrigation is similar for both the curves but the scheduling is different; it has to be highlighted that the farmer irrigation in 2016 start just in mid-July (following the usual managing of irrigation) whereas the model suggests to start irrigation at the beginning of July. Furthermore, the observed irrigation is higher than the simulated during the final stage of the crop development.

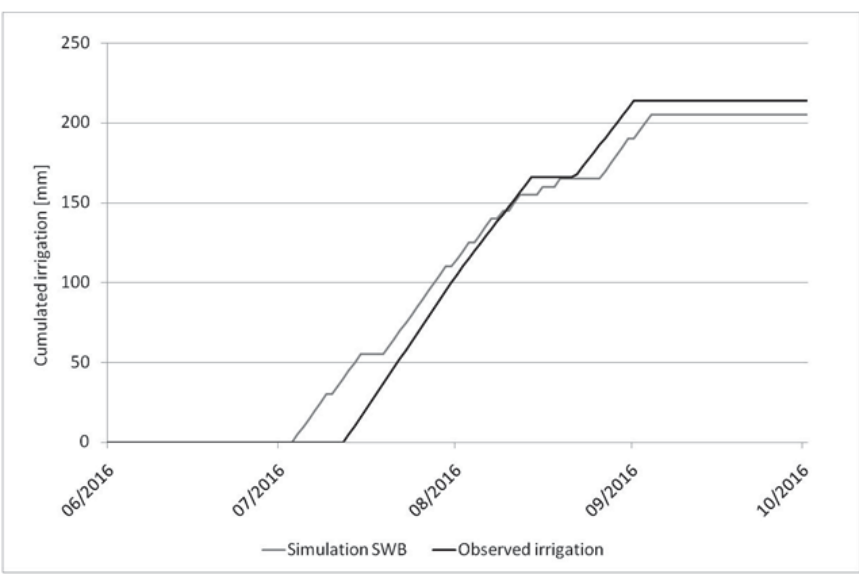

Fig. 5. Cumulated irrigation for 2016 for pear orchard (cv. Abate). Comparison between scheduling of irrigation simulated by SWB model and scheduling of observed irrigation; the SWB model results are plotted in gray, whereas the observed data are plotted in black

Fig. 6 shows the comparisons between SWB simulation and observed irrigation for two variables: Ks (continuous line) at the bottom and irrigation volume (histograms) at the top of the plot during 2016.A delay of 10 days of the observed irrigation start (histograms in black) occurred if compared with the irrigation simulated by the SWB model that started at the beginning of July. This delayhas caused a peak of water stress in the first part of July, whereas the observed irrigation in the following stages has been probably higher than the amount sufficient to maintain the crop in normal stress conditions. Note that the Ks drop to 0 for the observed irrigation whereas the Ks for the SWB simulation is maintained constant with peaks of 0.2 , tolerable for the crop.

2) Grapevine test case: Fig. 7 shows the total irrigation sum per year (from 2015 to 2017) for the vineyard test case simulated by the SWB in gray and actually distributed by the farmer in black. In this comparison, there are some remarkable differences between the two data series for all the three years. These discrepancies are due to external factors that guide the farmer decisions. In more details, the decisions regarding the irrigation are driven by constraints different from the actual water need of the plant: the behavior of the farmer is typically guided by economic decision and farm management. Despite this, the maximum value of annual total irrigation is reached in 2017 as in the SWB simulation with comparable values (32 $\mathrm{mm}$ of difference between the two data series).
To be noted that also for the pear study case 2017 was the most water demanding year (see Fig. 4) because the severe drought had a strong impact on crops since the early spring.

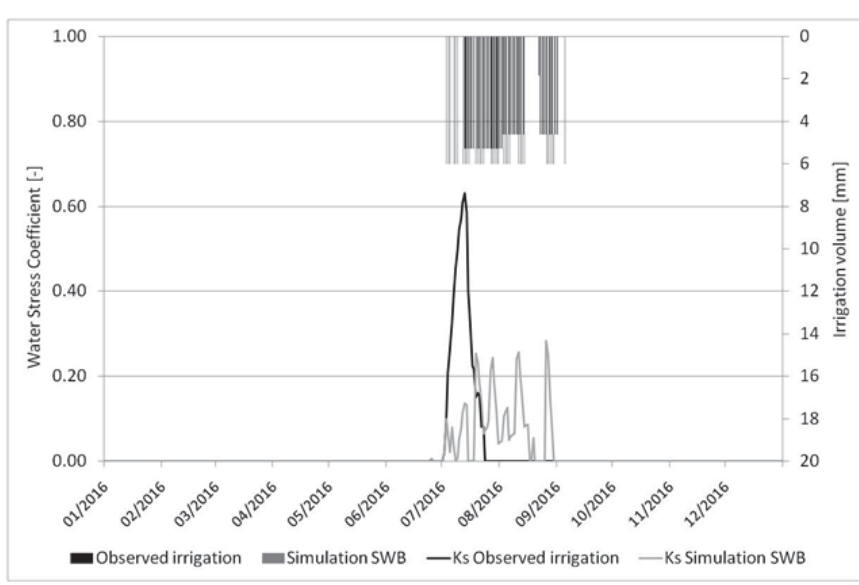

Fig. 6. Ks (water stress coefficient) for 2016 for pear orchard (cv. Abate). Ks (continuous line at the bottom of the plot)anddistributed irrigation (histograms at the top of the plot)are represented. The SWB model results are plotted in gray, whereas the observed data are plotted in black

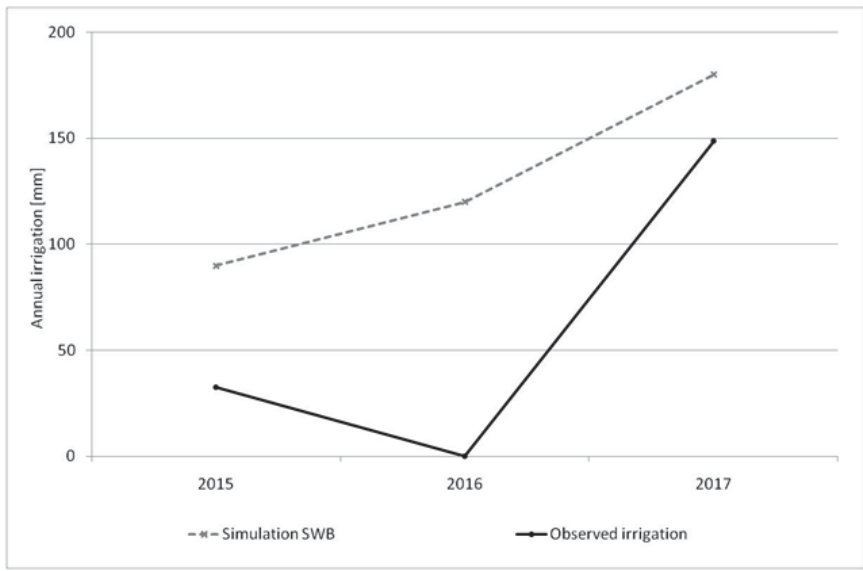

Fig. 7. Irrigation annual sum (mm) for vineyard (cv. Lambrusco Salamino) from 2015 to 2017. Comparison between simulation of SWB model and observed irrigation; the SWB model results are plotted in gray, whereas the observed data are plotted in black

In this case study the analysis is focused on 2017, an interesting season because, as mentioned before, the drought had strong impact on the water management for the vineyard.

For this case study the sprinkler irrigation method is adopted, so that for both the SWB simulation and observed data the values for each irrigation are higher and as a consequence less frequent than in the pear test case where drip irrigation is used. This irrigation regime is shown in more details inFig.8, where the irrigation scheduling (cumulated in $\mathrm{mm}$ ) for the two data series focused on the irrigation season 2017 (from May to October) are plotted. The gray line refers to simulated data whereas the black line refers to observed irrigation.

From this plot, it is shown that the farmer has performed only 2 irrigations: the first one is a high volume (more than 100 $\mathrm{mm}$ ) distributed on the $20^{\text {th }}$ of June, whereas the second one occurredon $24^{\text {th }}$ of August and it is probably a supplemental irrigation at the end of the season. On the contrary, the SWB model suggests a continuous series of lower irrigations. 


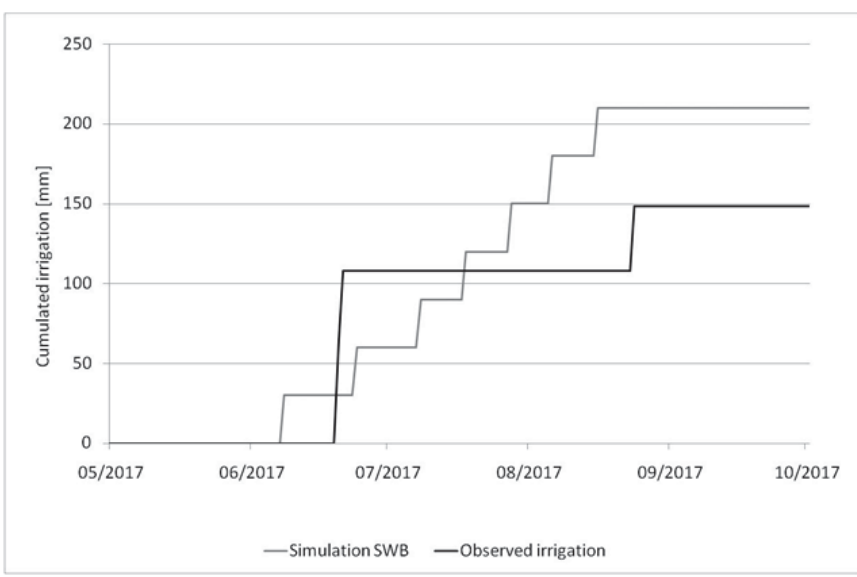

Fig. 8. Cumulated irrigation for 2017 for vineyard (cv. Lambrusco Salamino). Comparison between scheduling of irrigation simulated by SWB model and observed irrigation; the SWB model results are plotted in gray, whereas the observed data are plotted in black

The effects on crop of the two irrigation scheduling regimes are shown in Fig. 9, where the comparisons between SWB simulation and observed irrigation for Ks (at the bottom of the plot) and irrigation volume (at the top of the plot) are plotted for 2017.

The first observed irrigation of 2017 was higher than needed and probably a part of the water volume was lost in deep percolation. The lack of irrigation during the following 2 months generates a very high water stress that starts in mid July and decreases at the end of August because the farmer performs the supplementary irrigation. On the contrary, the Ks in the simulation of the SWB is maintained constant during the development of the crop; in September the Ks increases because before the harvest the irrigation is not allowed and the grapevine has overcome the stages of maximum sensibility to water stress.

\section{E. Discussion}

The analysis performed in the two study cases and the comparison between SWB simulation and observed irrigation are a proof of concept for the virtual digital twin development in the SWAMP project; this work is the first application of CRITERIA-1D on the pilot area of CBEC. The presented results allows to evaluate the performance of the SWB compared to the actual irrigations performed by farmers. From these analyses, it has been shown that the farmer decisions are rational but, in some cases, they do not respond to the dramatic climatic variability due to climate change. It means that the irrigation regime adopted by the farmer is no longer consistent with the current climate conditions, thus soil water balance models can be a support to address this issue.

Moreover, the described results show in some cases (e.g. the pear irrigation of 2016) that - even though the total irrigation during the year is similar for the SWB simulation and the observed irrigation - the scheduling is different and the SWB simulation maintain the crop to constant water stress conditions.

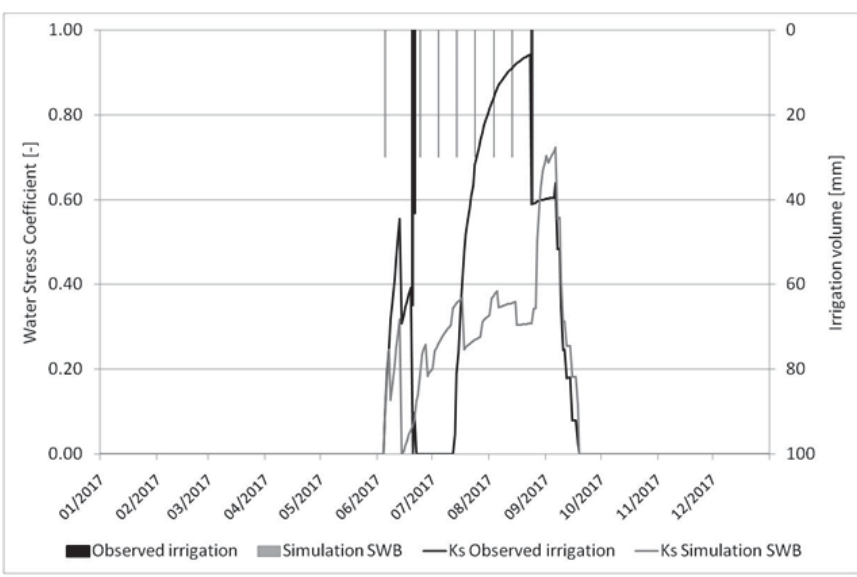

Fig. 9. Ks for 2017 for vineyard (cv. Lambrusco Salamino). Ks (continuous line at the bottom of the plot) and distributed irrigation (histograms at the top of the plot) are represented. The SWB model results are plotted in gray, whereas the observed data are plotted in black

\section{CONCLUSIONS}

The present work has shown that the application of CRITERIA-1D simulation model is a valid tool to support irrigation management because it allows abetter use of the resource avoiding crop yield losses with a rational irrigation scheduling.

However, this study results also as a preliminary validation of the CRITERIA-1D model, specific for the SWAMP platform and for the Italian pilot, but it will be fine-tuned in the forthcoming stages of the project. To analyticallyvalidate the model and the irrigation strategy, we are planning to use real data collected on field by smart sensors. In fact, ascrop parameters, CRITERIA-1D uses generic values available in literature, while it would be desirable to characterize the model with field specific values which describe these crop parameters in the most accurate way possible (e.g. measured values of Leaf Area Index - LAI with a multispectral camera, measured value of soil moisture in situ).

In addition, as mentioned before, the SWAMP project envisages in parallel the study of the crop irrigation needs and of the water distribution system optimization. It will therefore be imperative to evaluate an interplay between optimal irrigation values for the individual field and hydraulic constraints of the network to propose an actually implementable irrigation strategy, possibly defining a suboptimal data set of crop irrigation needs compatible with the organization of the network delivery.

Ultimately, it must be remembered that the SWAMP project aims at realizing a smart platform easily replicable and scalable for the irrigation management in different environments. In this sense, it will be interesting not only to evaluate the application of CRITERIA-1D in different areas (e.g.: pilots from other countries of the project), but also to validate different models for the same area: other widespreadmodels such as FAO AquaCrop or CROPWAT might be tested and integrated into the SWAMP platform. The integration of data driven models or of automatic control 
methods into the SWAMP platform might be evaluated as well.

\section{ACKNOWLEDGMENT}

This article has been written in the framework of SWAMP project. This project has received funding from the European Union's Horizon 2020 research and innovation programme under grant agreement No. 777112.

\section{REFERENCES}

[1] R. K., Pachauri, M.R.Allen, V.R.Barros, J.Broome, W. Cramer, R.Christ, ... and N.K.Dubash, Climate Change 2014: Synthesis Report. Contribution of Working Groups I, II and III to the Fifth Assessment Report of the Intergovernmental Panel on Climate Change. Geneva: IPCC,2014.

[2] P.Steduto, T. C.Hsiao, E. Fereres and D. Raes, Crop yield response to water, vol. 1028. Rome: Fao, 2012.

[3] M. Grieves, Michael and J. Vickers, "Digital Twin: Mitigating Unpredictable, Undesirable Emergent Behavior in Complex Systems", Transdisciplinary Perspectives on Complex Systems, 2017, pp. $85-113$.

[4] J.M. Norman and G.S. Campbell, An introduction to environmental biophysics. New York: Springer, 1998.

[5] H.V. Keulen, and N.G. Seligman,Simulation of water use, nitrogen nutrition and growth of a spring wheat crop. Wageningen: Pudoc, 1987.

[6] H.V. van Keulen and J. Wolf, Modelling of agricultural production: weather, soils and crops. Wageningen: Pudoc, 1986.

[7] K.S. Raju, and D.N. Kumar. "Irrigation planning using genetic algorithms",Water Resources Management,vol.18 (2), 2004, pp. 163 176.
[8] D. Rodríguez, J. Reca, J. Martínez, R. López-Luque, M. Urrestarazu,"Development of a new control algorithm for automatic irrigation scheduling in soilless culture", Applied Mathematics \& Information Sciences, vol.9(1), 2015, pp. 47.

[9] Y. Ding,L. Wang, L., Y. Li, D. Li, "Model predictive control and its application in agriculture: A review",Computers and Electronics in Agriculture, vol. 151, 2018, pp. 104-117.

[10] P.J. Kia, A.T. Far, M. Omid, R. Alimardani, L. Naderloo, "Intelligent control based fuzzy logic for automation of greenhouse irrigation system and evaluation in relation to conventional systems", World Applied Sciences Journal,vol. 6(1), 2009, pp. 16-23.

[11] V. Marletto, F. Ventura, G. Fontana,F. Tomei, "Wheat growth simulation and yield prediction with seasonal forecasts and a numerical model", Agricultural and forest meteorology,vol. 147(1-2), 2007, pp. 71-79.

[12] P.M. Driessen, "The water balance of the soil" in Modelling of agricultural production: weather, soils and crops.Wageningen: Pudoc, 1986.

[13] P.M. Driessen, N.T. Konijn NT, Land-use systems analysis. Wageningen: Pudoc, 1992.

[14] G. Villani, G., F. Tomei, F, R. Tomozeiu, R. V. Marletto, V. "Climatic scenarios and their impacts on irrigated agriculture in Emilia-Romagna, Italy",Italian J. Agrometeorol., vol. 16, 2011.

[15] R.G. Allen, L.S. Pereira, DRaes, M. Smith, M., Crop evapotranspiration-Guidelines for computing crop water requirements. Rome: Fao, 1998.

[16] F. Tomei, G.Antolini, R. Tomozeiu, V.Pavan, G.Villani, V.Marletto, "Analysis of precipitation in Emilia-Romagna (Italy) and impacts of climate change scenarios" in Proc. STAHY-WG International workshop, May 2010, pp. 23-25.

[17] N.I.C. Molina, J.P.V. Cunha, (2017). "A Distributed Parameter Approach for Sliding Mode Control of Soil Irrigation",IFACPapersOnLine, vol. 50(1), 2017, pp. 2714-2719. 